\title{
Interaction between Hydroxyphenyl-Containing Phosphate and Styrenic Resin
}

\author{
Hajime Nishihara, Susumu TanjI, and Ryuichiro Kanatani \\ Department of Styrenic Resins Development, Asahi Chemical Industry Co., Ltd., \\ Kawasaki-shi, Kanagawa 210, Japan
}

(Received May 29, 1996)

\begin{abstract}
Phosphates having $\triangle S P$ of 1 to 2 from a given resin were found to have partial compatibility with the resin. Such phosphates promote resin plastication and thus function as flow modifiers during molding while their partial incompatibility serves to maintain the inherent heat resistance of the resin in molded products. It was found in particular that hydroxyphenyl-containing phosphates such as resorcinyl diphenyl phosphate function not only as flame retardants but also as flow modifiers for styrenic resin compositions, in which they improve flowability without causing reduced impact resistance or heat resistance. Investigation of phosphate/styrenic resin compatibility by FT-IR spectroscopic and viscoelastic analysis indicated strong interaction by the phosphate containing no hydroxyphenyl group, but significantly weaker interaction by the hydroxyphenyl-containing phosphate.

KEY WORDS Styrenic Resin / Hydroxyphenyl-Containing phosphate / Resorcinyl Diphenyl Phosphate / Partial Compatibility / Solubility Parameter /
\end{abstract}

Halogenated compounds have predominantly been used as flame retardants for styrene-based resins. With increasing environmental consciousness in recent years, however, styrenic resins using non-halogenated flame retardants have been developed because of the possibility of hazardous gases being generated by halogenated flame retardants - particularly dioxins, which may result from decomposition of diphenylether-type halogen-based compounds. $^{1}$

Typical compositions of non-halogenated flame retardant styrenic resins are:

(a) rubber-modified polystyrene (HIPS), polyphenylene ether (PPE), and phosphorus-containing flame retardants ${ }^{2}$;

(b) polycarbonate (PC), ABS resin, and phosphoruscontaining flame retardants ${ }^{3}$; and

(c) HIPS and metal hydroxides.

We focused this study on compositions of type a), and particularly on obtaining the balance of propertiesimpact resistance, heat resistance, and melt flow-needed for flame retardant HIPS molding compounds.

Flame retardation of HIPS generally requires considerable amounts of phosphorus-containing flame retardants, which tends to cause a decline in impact resistance and heat resistance of HIPS. ${ }^{2}$ The addition of PPE to this polymer system as a flame retardation auxiliary improves the impact resistance and heat resistance, but adversely affects the melt flow, making it unsuitable for practical use.

Through the use of hydroxyphenyl-containing phosphate as the phosphorus-based flame retardant in system (a), we resolved these problems and successfully designed non-halogenated flame retardant polystyrene with excellent melt flow properties combined with impact resistance and heat resistance. ${ }^{4}$ This composition holds great promise for use as a molding compound for large-sized parts such as TV housings. ${ }^{5}$

\section{EXPERIMENTAL}

\section{Materials}

Resins. We used a graft polymer comprising polystyrene (PS) and polybutadiene (PB) (PS/PB-88/12 by weight) as HIPS; poly(oxy-2,6-dimethyl 1,4-phenylene) as PPE; and an acrylonitrile(A)-butadiene(B)-styrene(S) graft copolymer $(A / B / S=26 / 14 / 60$ by weight) as the ABS resin. These resins are manufactured and sold by Asahi Chemical Industry Co., Ltd., Japan.

\section{Preparation of Phosphates.}

(1) Resorcinyl Diphenyl Phosphate (TPP-OH)

In a flask were charged two parts phenol and 0.87 part aluminum chloride, and 100 parts phosphorus oxychloride were added dropwise at $90^{\circ} \mathrm{C}$ over 1 hour (phenol-aluminum chloride-phosphorus oxychloride molar ratio $=2.0: 0.01: 1.0$ ). To the intermediate product $(\mathrm{A})$ thus formed were added 71.7 parts (molar ratio: 1.0) of resorcinol to further continue the reaction. During the reaction, the temperature was gradually elevated to $180^{\circ} \mathrm{C}$ to complete esterification. The reaction product was cooled and washed with water. The catalyst and chlorine content were removed to obtain a phosphoric ester mixture (designated FR-1). By gel-permeation chromatography (GPC), the mixture was found to contain resorcinyl diphenyl phosphate, triphenyl phosphate, and resorcinol bis(diphenyl phosphate) at a ratio of 54.2 / $18.3 / 27.5$. The mixture (FR-1) was distilled, and fractionated by liquid chromatography to obtain resorcinyl diphenyl phosphate (TPP-OH).

(2) Other Phosphates

The procedure of FR-1 preparation was followed except that commercial alkylphenols or various alkylphenols obtained as previously described by "Encyclopedia of Chemical Technology"6 were used instead of phenol, in appropriate molar ratios for synthesis of the phosphates. The resulting phosphate mixtures were rinsed and purified by distillation or chromatography, essentially as described above.

(3) Summary List of Phosphates Prepared and Used 
Hydroxyl-containing phosphates: resorcinyl diphenyl phosphate (TPP-OH); phenyl diresorcinyl phosphate TPP- $(\mathrm{OH})_{2}$; hydroquinonyl diphenyl phosphate (XQ); phenyl nonylphenyl hydroquinonyl phosphate (NQ).

Phosphates containing no hydroxyphenyl group: triphenyl phosphate (TPP); bis(nonylphenyl) phenyl phosphate (DNP); resorcinol bis(diphenyl phosphate) (733S); bisphenol A bis(dicrezylphosphate) (741C); tris(nonylphenyl) phosphate (TNPP).

\section{Resin Compounding and Moloing}

The components of each resin composition shown in the tables and figures were mechanically mixed at the compounding ratios shown. The mixtures were melted in a Laboplastomill manufactured by Toyo Seiki Seisakusho, and compression molded to obtain the molded specimens.

\section{Measurements}

(1) Izod impact Strength: Measured in accordance with ASTM-D256 at $23^{\circ} \mathrm{C}$ using a V-notched 1/8-inch-thick specimen.

(2) Heat Resistance (Vicat Softening Temperature): Measured in accordance with ASTM-D1525.

(3) Melt Flow Rate (MFR): Determined in accordance with ISO-R1133 by measuring the extrusion rate at a temperature of $200^{\circ} \mathrm{C}$ and under a load of $5 \mathrm{~kg}$, and converting the value obtained to grams per 10 minutes.

(4) Flame Retardance: Evaluated by a vertical burning (VB) test in accordance with UL-94, using a 1/8-inch-thick specimen.

(5) $S P(\delta)$ (Solubility Parameter) and average SP:

(i) SP was calculated in accordance with the following Fedors formula from the known values of $\Delta e_{1}$ and $\Delta v_{1}{ }^{7}$ :

$$
\delta=\sqrt{\left[\sum\left(\Delta e_{1}\right) / \sum\left(\Delta v_{1}\right)\right]}
$$

wherein $\Delta e_{1}$ represents cohesive energy per unit functional group and $\Delta v_{1}$ represents molecular volume per unit functional group, and $\delta$ is expressed in $\left(\mathrm{cal} \mathrm{cm}^{-3}\right)^{1 / 2}$.

(ii) Average $\mathrm{SP}$ of the copolymer or copolymer blend was calculated from SP of different monomer units of the copolymer or component copolymers of the blend by proportional allocation of the respective SP of the monomer units or component copolymers in accordance with the weight ratios of monomer units or component copolymers, assuming the additivity rule to be applicable.

(6) Resin/phosphate compatibility: Compatibility of the phosphate with PS/PPE resin was evaluated by visual examination of cast film prepared from chloroform solution of PS/PPE (81/19 by weight)/phosphate compositions, and by solubility parameter (SP value), ${ }^{7}$ FT-IR, and viscoelasticity, and the results were compared for data correlation.

\section{RESULTS AND DISCUSSION}

Effects of Hydroxyphenyl-Containing Phosphate on Resin Properties

Figure 1 shows the relationship between MFR and Vicat softening temperature of resin compositions comprising HIPS, PPE, and different types of phosphates (74/26/31 by weight). Among the phosphates containing no hydroxyphenol group (TPP, DNP, 733S, 741C, and TNPP), the gain in heat resistance is inversely proportional to the decrease in melt flow. In contrast, the hydroxyphenyl-containing phosphates (NQ, XQ, and particularly TPP-OH) show a substantially higher ratio between increase in heat resistance and decrease in melt flow.

Figure 2 shows the relationship between the amount of phosphate added to HIPS/PPE (77/23) and the heat

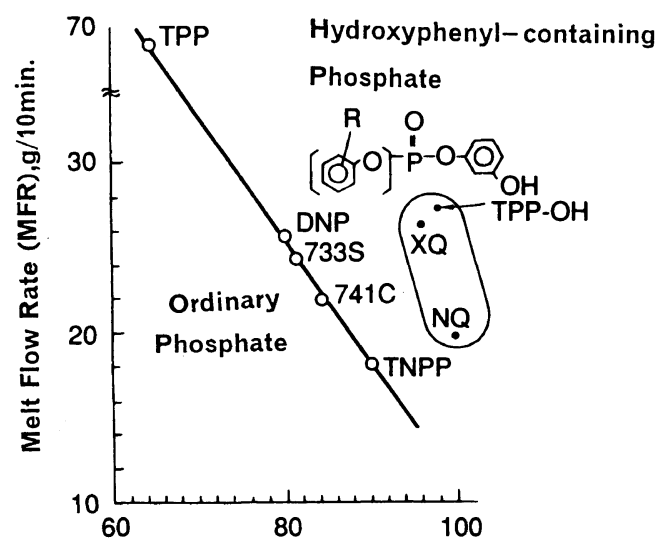

Heat Resistance (Vicat Sofetning Temp.), ${ }^{\circ} \mathrm{C}$

Figure 1. Heat resistance and melt flow of HIPS/PPE with various phosphates $(74 / 26 / 31$ by weight $)$.

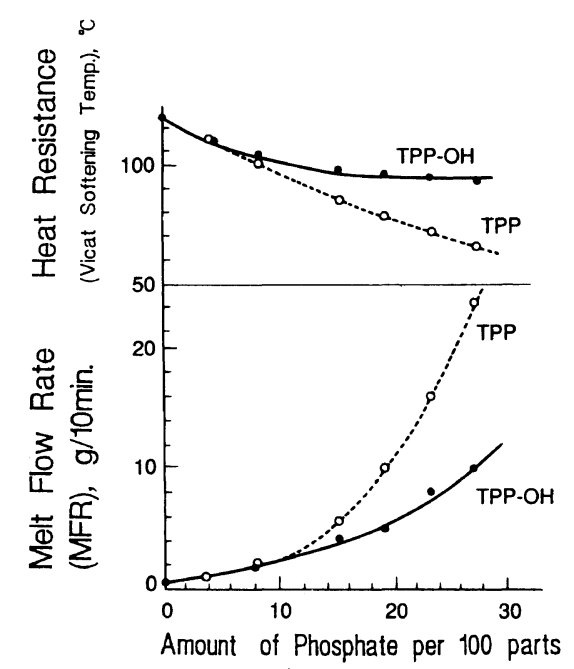

by Weight of HIPS/PPE (77/23) Resin
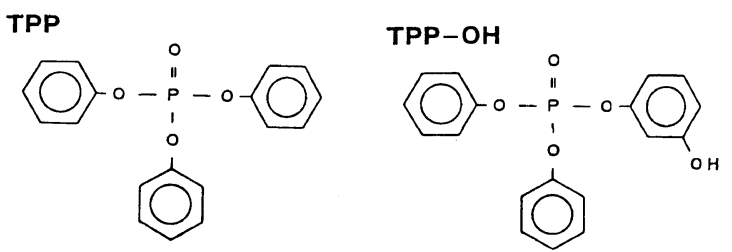

Figure 2. Melt flow and heat resistance of HIPS/PPE with various TPP-OH and TPP contents. 


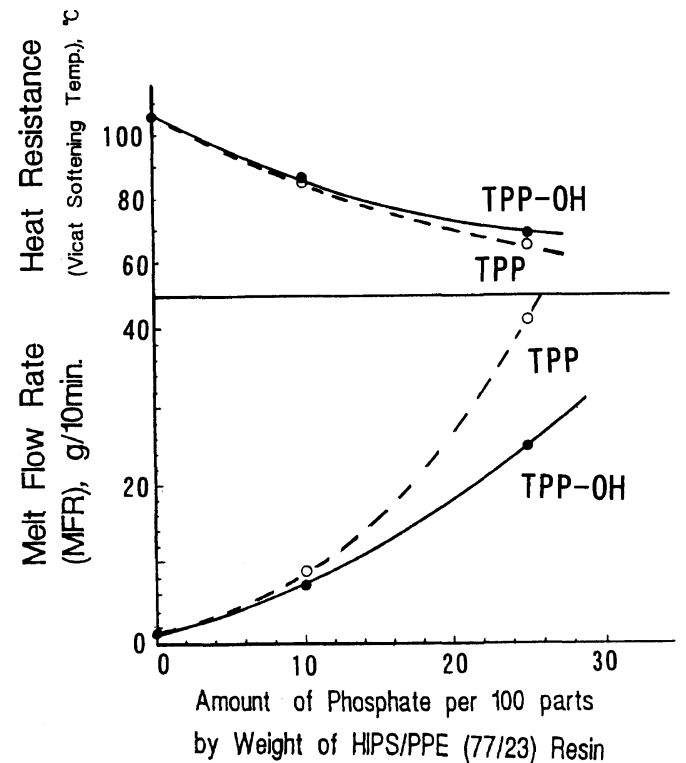

Figure 3. Melt flow and heat resistance of ABS resin with various TPP-OH and TPP contents.

resistance and melt flow of the resulting resin composition, for hydroxyphenyl-containing phosphate (TPP$\mathrm{OH}$ ) and phosphate containing no hydroxyphenol group (TPP). The effects of both phosphates are similar up to a content of about 10 parts by weight per 100 parts HIPS/PPE. With TPP, further increases in content result in a sharply increasing rise in melt flow but a nearly linear decrease in heat resistance MFR, throughout the measured range of up to 27 parts TPP by weight. With $\mathrm{TPP}-\mathrm{OH}$, the increase in melt flow is more moderate and the heat resistance is nearly constant throughout the range of approximately 15 to 27 parts TPP-OH per 100 parts HIPS/PPE by weight.

Figure 3 shows the effects of TPP-OH and TPP on ABS resin. Throughout the investigated range of up to 25 parts per 100 parts ABS resin by weight, the effects of the phosphates on this resin are similar, with rapidly increasing melt flow and decreasing heat resistance.

\section{Resin/Phosphate Compatibility}

We investigated resin/phosphate compatibility, in terms of the difference in their solubility parameters, as a means of elucidating the observed influence of TPP-OH and the other phosphates on the melt flow and Vicat softening temperature of the above resin compositions.

$\triangle S P$ as an Indicator of Compatibility. Figure 4 shows the relationship of $\triangle S P$, the difference between the average solubility parameter of PPE/PS (19/81 by weight) and that of a phosphate, and the solubility of the phosphate in the resin as evaluated by the film casting method. The $\Delta S P$ value [in $\left(\mathrm{cal} \mathrm{cm}^{-3}\right)^{1 / 2}$ ] clearly corresponded to the results of the film casting; the zone of phosphate solubility increased in correlation with the decrease in $\triangle S P$.

Effects of Number of Hydroxyphenyl Groups. Table I shows the effects of various phosphates on flame retardance, MFR, Izod impact strength, and Vicat softening temperature of resin composition. In the composition using TPP, where the number of hydroxyl groups is 0 , deterioration in heat resistance and impact resis-

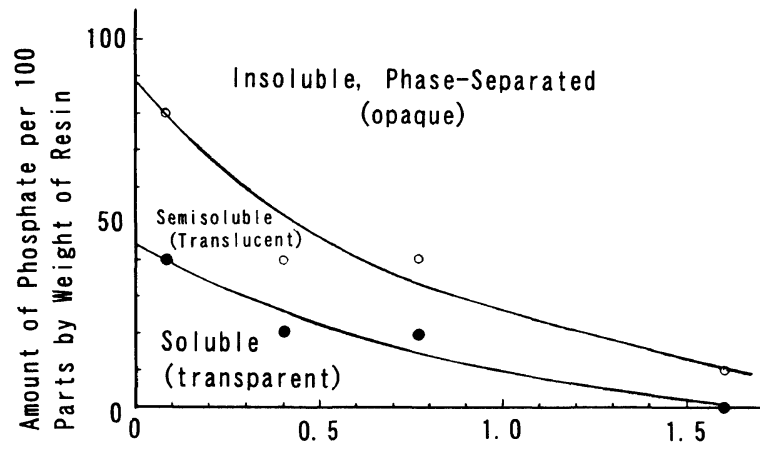

$\triangle S P$ between Resin and Phosphate Resin:PPE/PS (19/81 by weight)

Figure 4. SP difference $(\triangle S P)$ between PPE/PS resin and phosphates, and solubility of phosphates in the resin.

Table I. Effects of the number of hydroxyl groups in the phosphate

\begin{tabular}{|c|c|c|c|c|c|c|}
\hline \multirow[t]{2}{*}{ Phosphate } & \multirow[t]{2}{*}{$\Delta S P^{\mathrm{a}}$} & \multirow{2}{*}{$\begin{array}{l}\text { Flame } \\
\text { retar- } \\
\text { dance } \\
\text { UL94 }\end{array}$} & $\frac{\text { MFR }}{g / 10 \min }$ & $\begin{array}{c}\text { Izod } \\
\text { impact } \\
\text { strength }\end{array}$ & $\begin{array}{c}\text { Vicat } \\
\text { softening }\end{array}$ & \multirow{2}{*}{$\begin{array}{l}\text { Compati- } \\
\text { bility with } \\
\text { resin }\end{array}$} \\
\hline & & & & $\overline{\mathrm{kg} \mathrm{cm} \mathrm{cm}^{-1}}$ & Temp. $/{ }^{\circ} \mathrm{C}$ & \\
\hline TPP & 0.2 & V-0 & 10.4 & 5.3 & 76 & Good \\
\hline TPP-OH & 1.8 & V-0 & 8.1 & 10.1 & 97 & Good \\
\hline $\mathrm{TPP}-(\mathrm{OH})_{2}$ & 3.2 & $\mathrm{HB}^{\mathrm{b}}$ & 1.7 & 7.0 & 116 & $\begin{array}{l}\text { Phase } \\
\text { separation }\end{array}$ \\
\hline
\end{tabular}

${ }^{a} \mathrm{SP}$ difference between resin and phosphate. ${ }^{\mathrm{b}}$ No attainment of UL-94 (V-O, V-1, or V-2) rating. Resin composition: HIPS/PPE/ phosphate/melamine $(80 / 20 / 20 / 16$ by weight $)$.

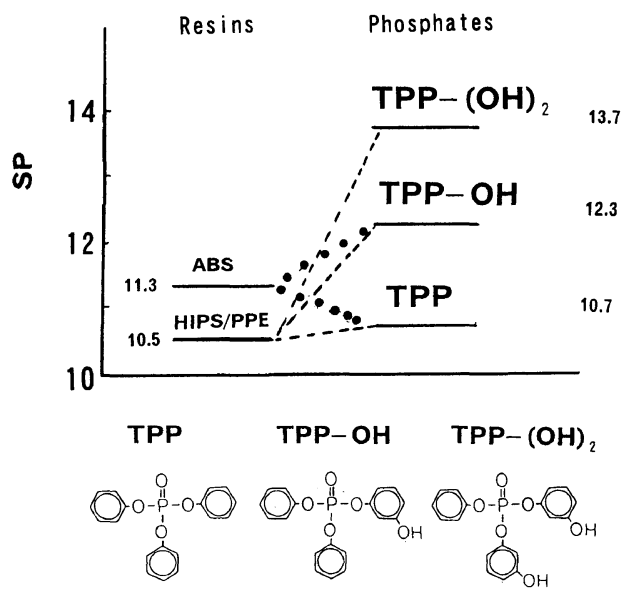

Figure 5. SP of resins and phosphates.

tance is notable although the melt flow is remarkably improved. In the composition using TPP- $(\mathrm{OH})_{2}$, where the number of hydroxyl groups is 2 , the hydroxyphenolcontaining phosphate is phase-separated because of low compatibility with the resin, thus resulting in deterioration of melt flow. In the composition using TPP-OH, where the number of hydroxyl groups is 1 , melt flow is improved while heat resistance and impact resistance are maintained.

In Figure 5 , the SP values of the HIPS/PPE ( $80 / 20$ by weight) and ABS resins are compared with those of TPP, TPP-OH, and TPP- $(\mathrm{OH})_{2}$. The SP of the HIPS/PPE resin is very close to that of TPP $(\triangle \mathrm{SP}=0.2)$, moderately different from that of TPP- $(\mathrm{OH})(\Delta S P=1.8)$, and largely 


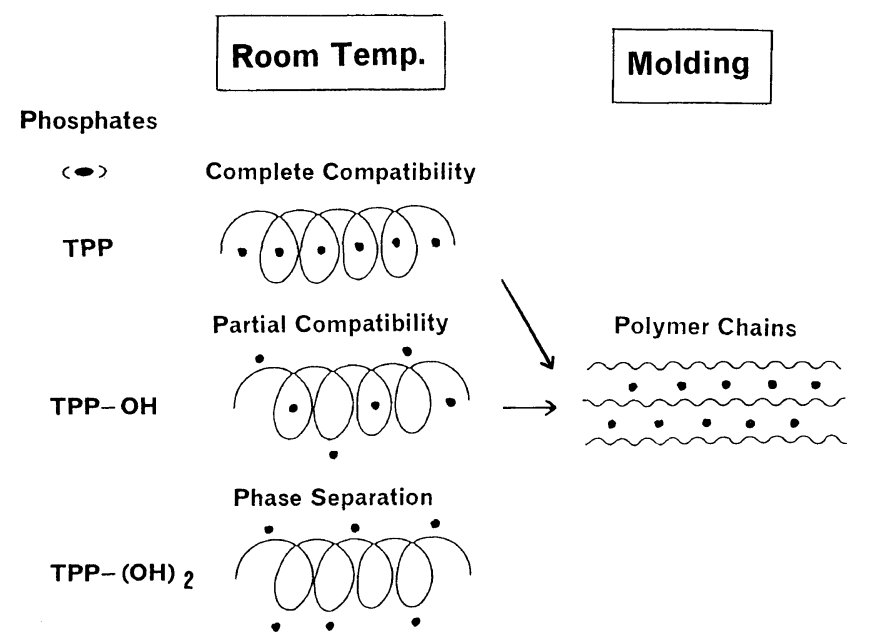

Figure 6. Schematic comparison of compatibility between phosphates and polymer.

Table II. FT-IR spectroscopic data ${ }^{a}$

\begin{tabular}{|c|c|c|c|c|c|}
\hline \multirow{3}{*}{$\begin{array}{l}\text { Absorbance } \\
\text { of polystyrene }\end{array}$} & \multirow{3}{*}{$\begin{array}{c}\text { Base resin } \\
\text { PPE/PS } \\
23 / 77 \\
v_{0}\end{array}$} & \multicolumn{4}{|c|}{ Resin composition } \\
\hline & & \multicolumn{2}{|c|}{$\begin{array}{c}\mathrm{PPE} / \mathrm{PS} / \mathrm{TPP} \\
23 / 77 / 19\end{array}$} & \multicolumn{2}{|c|}{$\begin{array}{c}\mathrm{PPE} / \mathrm{PS} / \mathrm{TPP}-\mathrm{OH} \\
23 / 77 / 19\end{array}$} \\
\hline & & $v$ & $\Delta v$ & $v$ & $\Delta v$ \\
\hline $\begin{array}{l}\mathrm{CH}_{2} \text { Stretching } \\
\text { vibration }\end{array}$ & 2921.7 & 2923.6 & 1.9 & 2921.7 & 0 \\
\hline $\begin{array}{l}\mathrm{CH} \text { Bending } \\
\text { vibration }\end{array}$ & 1022.1 & 1026.0 & 3.9 & 1024.0 & 1.9 \\
\hline
\end{tabular}

${ }^{\mathrm{a}} \Delta v:\left|v-v_{0}\right|$.

different from that of TPP- $(\mathrm{OH})_{2}(\triangle S P=3.2)$. Based on the results shown in Table I and Figure 5, the HIPS/PPE resin exhibits complete compatibility with TPP because of small $\Delta S P$, partial compatibility with TPP-OH because of moderate $\triangle S P$, and virtually no compatibility with TPP- $(\mathrm{OH})_{2}$, and thus phase separation, because of large $\triangle S P$.

The SP of ABS resin is very close to that of TPP and TPP-OH $(\triangle S P=0.6$ and 1.0 , respectively), and therefore the ABS resin has complete compatibility with TPP and TPP-OH. For this reason, ABS resin compositions containing TPP-OH and TPP are similar in MFR and Vicat softening temperature (Figure 3).

Phosphates having $\triangle S P$ of 1 to 2 from a given resin were found to have partial compatibility with the resin. Such phosphates promote resin plastication and thus function as flow modifiers during molding, while their partial incompatibility permits the retention of the inherent heat resistance of the resin in molded products.

Figure 6 schematically compares polymer/phosphate compatibility - complete compatibility, partial compatibility, and phase separation. TPP has good compatibility with the polymer and is dispersed uniformly, but TPP- $(\mathrm{OH})_{2}$ has very poor compatibility with the polymer and is phase-separated. TPP-OH has moderate compatibility with the polymer, and therefore functions as a plasticizer during molding but does not decrease the

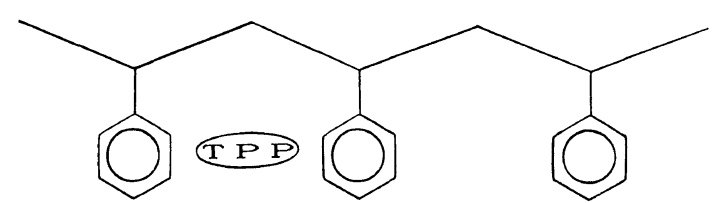

Strong Interaction

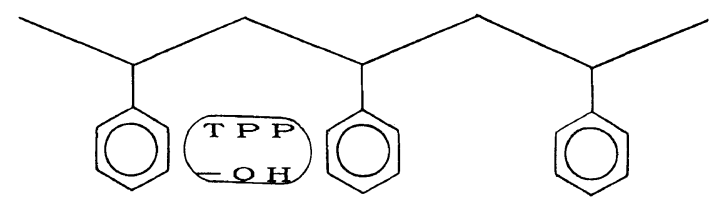

Weak Interaction

Figure 7. Schematic comparison of polystyrene interactions with TPP and TPP-OH.

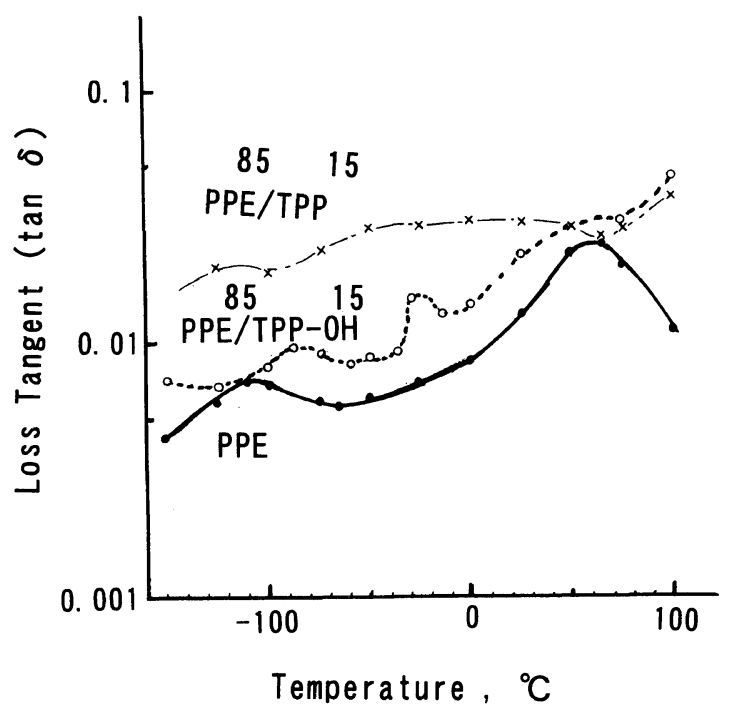

Figure 8. Effects of PPE/phosphate interaction on viscoelastic behavior.

heat resistance of the polymer in the range of its service temperatures.

Analysis of Interaction between Resin and Phosphate. Assuming the scheme of Figure 6 to be correct, TPP may be expected to interact strongly with the polymer, and TPP-OH more weakly.

Table II shows FT-IR data for a HIPS/PPE base resin and for resin compositions comprising HIPS/PPE/TPP and HIPS/PPE/TPP-OH. These data indicate that the resin composition containing TPP shifts to higher wavelengths in the $\mathrm{CH}_{2}$ and $\mathrm{CH}$ bands of polystyrene, compared with that containing TPP-OH, thus showing TPP to have a stronger interaction with polystyrene than TPP-OH.

Figure 7 shows a schematic comparison of the interaction of polystyrene with TPP and with TPP-OH.

Figure 8 shows the viscoelastic behavior (loss tangent vs. temperature) of PPE, PPE/TPP (85/15 by weight), and PPE/TPP-OH ( $85 / 15$ by weight). The resin composition containing TPP-OH clearly exhibits a peak around $-100^{\circ} \mathrm{C}$ derived from PPE and a peak around $-30^{\circ} \mathrm{C}$ derived from TPP-OH. The resin composition containing TPP exhibits a broad absorption, with no observable peak at either $-100^{\circ} \mathrm{C}$ (PPE) or $50^{\circ} \mathrm{C}$ (TPP), 
thus showing TPP-OH to have a substantially weaker interaction than TPP with PPE.

\section{REFERENCES}

1. U. Reichert, Kunstsoffe German Plastics, 83 (10), 11 (1993).

2. G. F. Lee, Jr., U.S. Patent 4684682 (1987); H. Feldmann and S. Vestner, Eur. Patent 311909 (1989).

3. K. Muehlbach and G. Mckee, U.S. Patent 4914144 (1990).

4. H. Nishihara, U.S. Patent 5278212 (1994); H. Nishihara, Preprints, SPSJ The 3rd ABC Kenkyu Toronkai (symposium), 1994, p 37-38; H. Nishihara, FRCA (Fire Retardant Chemicals
Association) International Conference Report, (Florida March, 1995), p 79-96; H. Nishihara, Polym. Prepr., Jpn., 44, (No. 4), 555 (1995); English Edition: Vol. 44, Nos. 1-5, E175 (1995); H. Nishihara, Preprints, Styrenics '96; MAACK Business Services, Plastics Technology and Marketing 3rd Annual World Congress, Zurich, June, 1996; H. Nishihara, "Fine Chemicals", CMC Ltd., Ed., Tokyo, Japan, 41-53, Vol. 25, No. 1, Jan. (1996).

5. H. Nishihara, Jpn. Patent 5-295249 (Chem. Abstr., 120, 272725w, 1994).

6. H. W. B. Reed, "Encyclopedia of Chemical Technology", third edition, Volume 2, 'Alkylphenols', (A Wiley - Interscience Publication, John Wiley \& Sons, New York, 1978), pp 72-96.

7. R. F. Fedors, Polym. Eng. \& Sci., 14(2), 147 (1974). 